\title{
Spirou
}

\section{Yves Chaland}

Dibbuks, 2016

\section{L}

A lectura del Spirou de Yves Chaland produce, por decirprofunda irritación. La razón principal es bien sencilla: nos deja con la miel en los labios. Pero hay otra: Corazones de acero, que así se le bautizó a posteriori, es uno de los ejemplos más evidentes de cómo la maquinaria empresarial puede imponerse sobre la libertad de los autores.

Vayamos por partes. Al joven historietista lionés se le propuso, desde la redacción del semanario señero de Dupuis, la realización de una nueva historieta de Spirou y Fantasio. Acepta entusiasmado, y con su incorporación, en 1982, llega un momento en el que coinciden tres equipos creativos diferentes haciéndose cargo de un mismo personaje. El dueto Nic Broca y Raoul Cauvin, por un lado, la pareja formada por Philippe Tome y Jean-Richard Geurts, alias Janry, por otro, y él mismo. El motivo de esa sobreexposición de la estrella de la editorial es precisamente lograr que cada semana aparezcan en la revista nuevas páginas del intrépido botones. Como es lógico, esa estrategia no podía funcionar durante demasiado tiempo, y la víctima propiciatoria acabará siendo el último en llegar. De ese modo, y por decisiones estrictamente editoriales, la obra restará inacabada, convirtiéndose en una muestra de lo que pudo haber sido, y no le dejaron que fuera. Durante los años inmediatamente posteriores, Chaland y sus cómplices (Yann Lepennetier, Isabelle Beaumenay-Joannet) presionan para que les dejen concluir su obra, o, todavía mejor, rehacerla; sin embargo, para Dupuis, esas planchas, convertidas, casi, en leyenda (circulaban, de hecho, ediciones pirata), son algo así como un hijo no reconocido del que se quieren desentender. Como mucho, conseguirán el permiso para reeditarlas, pero, por extraño que parezca, no dentro del sello propietario de Spirou, sino a través de una editorial independiente, Champaka, propiedad de un colega, Éric Verhoest. La recopilación verá la luz justo a tiempo, tres meses antes del fallecimiento de Chaland en un accidente automovilístico.

Para aquellos que ya hayan leído la excelente edición de Dibbuks, la anterior introducción, me temo, les habrá servido de muy poco. Junto a las veinticuatro tiras originales, el libro 
incluye un apasionante y ameno ensayo (dividido en dos partes, a modo de prólogo y de epílogo) firmado por José-Louis Bocquet y titulado «La verdadera historia del Spirou de Chaland». Bocquet es, como bien saben, novelista y guionista de historietas, gran conocedor de la historia de la BD francobelga, y especialmente de la carrera de André Franquin (no solo se ha encargado de coordinar y comentar las reediciones de algunas de las obras magnas del creador del Marsupilami, caso de Bravo les Brothers o de La foire aux gangsters, sino también de repasar, a cuatro manos con el propio Verhoest, la fecunda carrera de aquel en Chronologie d'une oeuvre). Aunque sería exagerado afirmar que, como escritor de ficción, está especializado en un género concreto, es evidente que dentro de su producción destacan los cómics biográficos. Entre ellos, por ejemplo, sus colaboraciones con la ilustradora Catel Muller, la multipremiada Kiki de Montparnasse u Olympe de Gouges, ambas traducidas por Sins Entido, y ese sintético y entretenidísimo acercamiento al padre de Tintín, que fue Las aventuras de Hergé, realizado al alimón junto con Jean-Luc Fromental, Stanislas B. y Madeleine DeMille. Pues bien, como decía, todo lo apuntado en el párrafo anterior lo explica, mejor y, como suele decirse, con todo lujo de detalles, el propio Bocquet en su texto. Ese artículo logra contextualizar la obra, dotarla de sentido, al tiempo que traza un esbozo del funcionamiento de la principal industria europea del cómic, al menos por aquel entonces. Bocquet sabe perfectamente de qué está hablando, y así consigue dar forma al complemento que Corazones de acero merece.

En lo que respecta a la historieta en sí, quien conozca la fulgurante trayectoria de Chaland intuirá qué va a encontrarse, siendo como fue plenamente coherente. Desde sus primeros pasos en Métal Hurlant, con veintiún años, hasta el último tebeo de Las aventuras de Freddy Lombard, demostrará en todo momento una devoción incondicional hacia los grandes historietistas belgas de las generaciones anteriores a la Segunda Guerra Mundial, la de Jijé y la de la escuela de Marcinelle (Tilleux y Franquin por bandera). Admira también a Hergé, no hay duda, pero no es su fuente de inspiración, o, al menos, no la más importante. Sus creaciones, sus escenarios, están directamente influidos por los de sus maestros, hasta el punto de que son la evolución lógica de aquellos, el estadio definitivo. Bob Fish, Albertito, el trío conformado por Freddy, Dina y Sweep, descienden, por vía directa, de Gil Pupila, de Libélula, de Félix, Modesto y Pompón, sometidos a una cura de rejuvenecimiento y adaptados a los nuevos tiempos. No obstante, entre unos y otros hay un elocuente contraste, su elenco de héroes, a diferencia del de sus lecturas de infancia, parecen haber perdido la esperanza en el futuro, en ese futuro que se les prometió durante la posguerra. $Y$ otro tanto sucede con los escenarios elegidos. La Bruselas de Chaland, tomada como modelo de una ciudad de tebeo a partir de la que conoció a través de las viñetas, es totalmente irreal, ucrónica. Cronológicamente se remontará siempre a las décadas de 1950 y 1960, pero sin intención de ser fiel a la realidad, con barrios todavía reconstruyéndose, con solares tapiados, con chatarreros recogiendo escombros, con comercios sucios y vetustos.

Algo muy parecido sucederá con su revisión de Spirou (un experimento que hoy encajaría a las mil maravillas en la colección Le Spirou de...). Obviando, como bien apunta Bocquet, la popular etapa de Franquin con el personaje, Chaland se remite a la vieja versión de Jijé, algo más ingenua, para plantear una comedia ligera en apariencia, aunque con cierto aire 


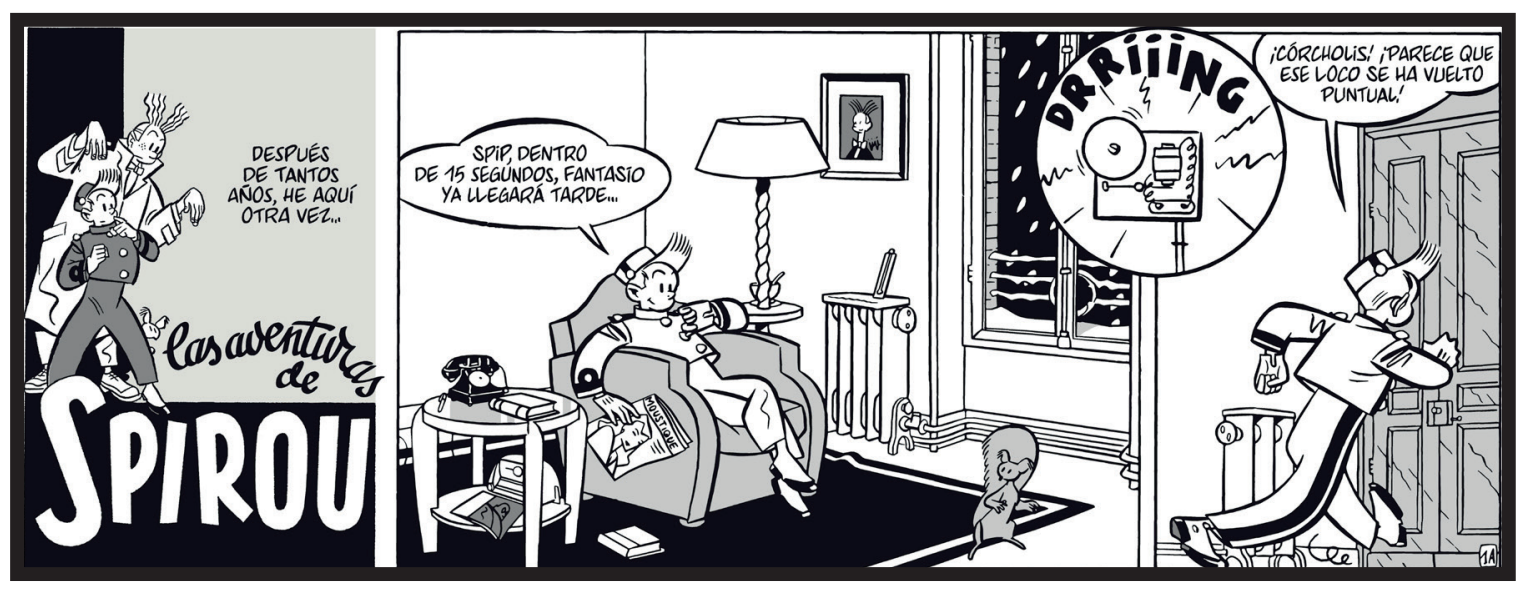

pesimista: las primeras tiras describen un invierno frío y duro, la violencia está presente desde el arranque, el protagonista se imagina - por un segundo- su propio funeral, la mayoría de gente que interactúa con Spirou y Fantasio es desconfiada, se cierne sobre ellos la sombra amenazante de una gran corporación que no está jugando limpio. Sin embargo, nada de todo eso se plantea con seriedad; al contrario, es una chanza, una aventura que obvia las explicaciones innecesarias. La casualidad juega un papel fundamental, al igual que las coincidencias (el rol negativo lo interpreta un antiguo compañero de escuela de Fantasio) y los malentendidos. Tampoco hallaremos viñetas vacuas o transiciones interminables. No hay escena en la que no se nos aporte información, incluso hay muchas en las que la acción se desarrolla en varios planos al mismo tiempo. El ritmo es continuo. Las presentaciones no son más que una pérdida de tiempo, parece pensar Chaland, así que vayamos al grano. Quien no conozca el espacio o a los actores ya se familiarizará con ellos más adelante.

En una historieta de estas características no podía faltar el viaje exótico. Tras la confusión inicial, conocerán a Georges Leopold, un viejo aristócrata, nostálgico de los tiempos coloniales (¿recuerda a un Tintín entrado en años?), que les encargará encontrar a Bocongo, su antiguo criado. Para ello deberán viajar hasta África, en concreto al imaginario Estado de Urugondolo, un territorio rico en yacimientos diamantíferos, modelo de modernidad y conocido como «el país más democrático del planeta». Y en ese punto, mientras los protagonistas están intentando averiguar cómo entrarán allí, se clausuró el proyecto. La última tira, de hecho, es un simple resumen que enlaza lo acontecido hasta entonces con lo que podría pasar en una hipotética segunda parte.

Paradójicamente, y sin que fuera esa su intención, las circunstancias que rodearon la abrupta publicación de Corazones de acero han acabado por dotar a este tebeo de un espíritu familiar para los lectores criados antes de la última (de momento) revolución tecnológica. El propio Chaland lo explicaba en las entrevistas concedidas, y lo puso en práctica en su primer trabajo de envergadura, Captivant, editado a finales de los setenta por Les Humanoïdes Associés. Se trataba de lo que podríamos denominar «la sensación de la lectura intermitente». Actualmente, el acceso a las colecciones abiertas, a las novedades, a los ejemplares atrasados, es relativamente fácil, y los compradores habituales pueden controlar en todo momento la 
fecha de salida de los títulos que les interesan. No obstante, hasta los años noventa, aproximadamente, la distribución, fuera de las grandes ciudades, sumada a los propios hábitos de consumo de los lectores, dificultaba el seguimiento ininterrumpido y sistemático de las series o de los personajes favoritos, creando enormes vacíos argumentales que se llenaban normalmente con la propia imaginación. «Tenía primos en el campo, y en su casa había muchos álbumes en mal estado, y números de Spirou incompletos» —aclara Chaland—, «en mi primer álbum, Captivant, intenté recuperar ese ambiente, evocar esos fragmentos de historia de dos o tres páginas, episodios que no empezaban ni terminaban». Algo muy similar a lo que declaraba el guionista Santiago García a Daniel Ausente en una conversación publicada en Canino a propósito de la aparición del libro Cómics sensacionales:

\begin{abstract}
Una cosa que me ha fascinado siempre es que durante la infancia leíamos los cómics incompletos, que es algo que siempre pasaba. Nunca podías leer una serie entera de principio al final, había cosas que no sabías y por eso nos gustaban tanto las referencias tipo «como se vio en el episodio 24». Te preguntabas dónde estaría ese episodio, si lo habías visto. Con los cómics franceses también pasaba muchas veces que faltaban páginas o tenían las tapas arrancadas. En los de Novaro mexicanos se anunciaban las portadas de otros tebeos, que a lo mejor nunca llegarían a España, y siempre imaginabas que serían maravillosos [...] no leíamos las cosas por orden sino que te caían y además incompletas. ${ }^{1}$
\end{abstract}

Hay también una última consecuencia positiva de la cancelación inesperada de Corazones de acero, y de la negativa de Dupuis a concederle una continuación. Entre los planes que Chaland y Yann manejaron para reanudarla, llegaron a plantear varias ideas, plasmadas algunas de ellas en varias páginas de muestra, que con el tiempo se concretarían en dos historietas mayúsculas. Una, la más reciente, fue El botones de verde caqui, de Yann y Olivier Schwartz, un homenaje sentido y original a sus mentores. Y la otra, alejada del microcosmos de Spirou, fue $F-52$, el último título de Freddy Lombard, un claustrofóbico misterio, a bordo de un avión propulsado por energía atómica, que supuso el testamento final de su creador, y una nueva demostración de su genialidad.

Óscar Gual

Óscar Gual (1973), bibliotecario de profesión, viene colaborando en diferentes medios especializados en el mundo del cómic como Tebeosfera o Entrecomics. Es, además, autor del libro Viñetas de posguerra: Los cómics como fuente para el estudio de la historia (2013).

1 Ausente, D. «[Entrevista] Santiago García: "Los aficionados al cómic nos aferramos a criterios marcados por un niño de 11 años"», en Canino. Disponible online en http://www.caninomag.es/entrevista-santiago-garcia-los-aficionados-al-comic-nos-aferramos-a-criterios-que-marcaron-a-un-nino-de-11-anos/. 